\title{
Study of CRFP Shell Structures under Dynamic Loading in Shock Tube Setup
}

\author{
H. A. Khawaja, ${ }^{1}$ T. A. Bertelsen, ${ }^{2}$ R. Andreassen, ${ }^{3}$ and M. Moatamedi ${ }^{3}$ \\ ${ }^{1}$ Department of Engineering and Safety, University of Tromsø, Tromsø, Norway \\ ${ }^{2}$ Kongsberg Defence \& Aerospace AS, Kirkegårdsveien 45, 3616 Kongsberg, Norway \\ ${ }^{3}$ Faculty of Technology, Narvik University College, Narvik, Norway \\ Correspondence should be addressed to H. A. Khawaja; hassan.a.khawaja@uit.no
}

Received 4 August 2014; Accepted 16 November 2014; Published 4 December 2014

Academic Editor: Zhongwei Guan

Copyright (C) $2014 \mathrm{H}$. A. Khawaja et al. This is an open access article distributed under the Creative Commons Attribution License, which permits unrestricted use, distribution, and reproduction in any medium, provided the original work is properly cited.

\begin{abstract}
The paper gives the study of the response of carbon fiber reinforced polymers (CRFP) quasi-isotropic shell structures under the influence of dynamic loading. The quasi-isotropic CRFP shell specimens are fabricated using Multipreg E720 laminates. These laminates are laid in such a way that shell structure has equal strength and mechanical properties in the two-dimensional (2D) plane and hence can be regarded as quasi-isotropic. In this study, the dynamic loading is generated using shock waves in a shock tube experimental setup. The strain and pressure data is collected from the experiments. Additional tests are carried out using Material Test System (MTS) for both tensile and flexural response of CRFP. Results obtained from experiments are compared with numerical simulations using ANSYS Multiphysics 14.0 finite element method (FEM) package. The numerical simulation and experimental results are found to be in good agreement.
\end{abstract}

\section{Introduction}

The composite materials are increasingly used in a number of applications, for example, ultralight tennis rackets, aircrafts fuselages, sports cars, and so forth. With the increase in usage of composites, it is also becoming essential to study them [1]. This paper presents an attempt to study the carbon fiber reinforced polymers (CRFP) under the influence of dynamic loading using shock waves generated in shock tube experimental setup.

Researchers have tested various materials subjected to shock wave [2]. Usually, such experiments are carried out using explosives submerged in water $[3,4]$. The test specimens are placed at different distances to control the intensity of shock waves $[5,6]$. This method is both expensive and potentially dangerous and requires careful planning $[3,7]$. In addition, complicated calculations and estimations are required to analyze the results. Another method is based on creating shock waves in a shock tube [8]. Such method has considerable advantages in comparison to earlier methods [9, 10]. In this method, either a solid projectile or a high pressure fluid is injected into a tube containing liquid instantaneously. This generates a shock wave which propagates along the tube. A test specimen subjected to the shock wave can be placed along the tube. The intensity of shock wave is controlled using velocity of entering projectile or the pressure of fluid. Further control can be added using a T-junction in the tube [9]. Pressure transducers and strain gauges can be placed along the tube for the collection of data. The shock tube experimental setup used in this study is given in Section 2.

\section{Methodology}

2.1. Preparation of CFRP Samples. For this study, quasiisotropic shell structures are made by strengthening fibers in all respective $45^{\circ}$ angles. A quasi-isotropic shell structure consists of a lay-up of laminates at $0^{\circ},+45^{\circ},+90^{\circ},-45^{\circ}\left(135^{\circ}\right)$, $0^{\circ}$, and so on as shown in Figure 1. This makes the composite shell structure equally strong in two-dimensional (2D) plane. Different strengths and mechanical properties can be obtained by laying fabrics in different angular positions [11]. This is useful if required in particular application [12]. 


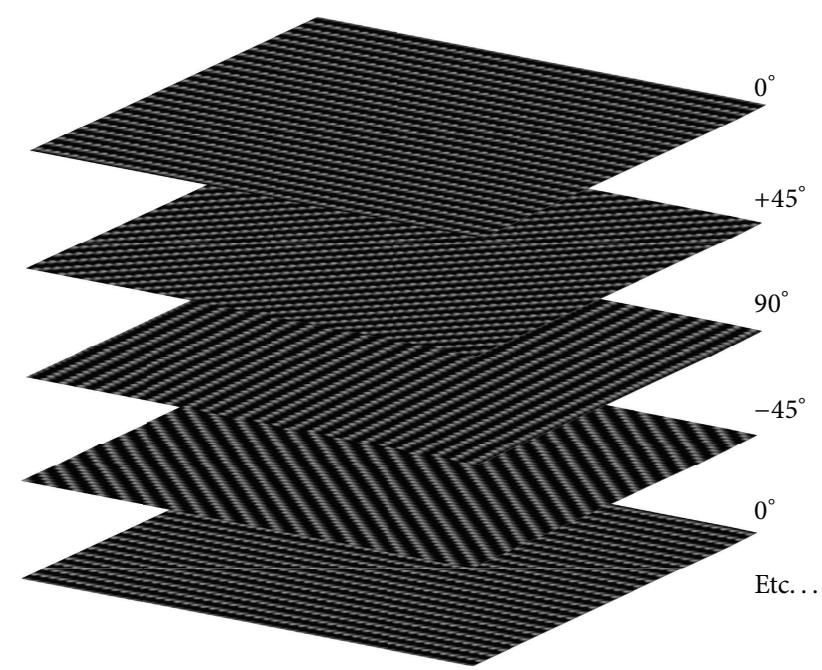

FIGURE 1: A 3D model showing a quasi-isotropic lay-up of carbon fiber fabrics.

In this work, carbon fiber reinforced polymers (CRFP) shell specimens are fabricated using Multipreg E720 laminates [13]. These laminates consist of two main components, carbon fiber fabric (T-300) and a matrix material (SC72A/ EF72 $[14,15])$. The matrix material (also known as resin) is an adhesive material, which helps to glue carbon fiber fabrics together. The matrix material also aids in increasing the stiffness and strength of the composite material. A generic tensile stress/strain behavior of fibers, resin, and composite is given in Figure 2 [16]. The failure mechanism of composite material is given by [17].

2.2. Shock Tube Experiment Setup. The shock tube consists of two main parts: the driver section and the driven section (Figure 3) [18]. The driver section contains compressed air, which is released into the driven section in order to create a shock wave. This is generally triggered with a burst plate or a high speed valve. In given experiments, shock wave is generated in water by releasing high pressure air through high speed valve. The shock wave propagates through water in the driven section [19]. At the end of the driven section, a Tsection is fitted, enabling a secure mount of a test specimen (Figure 4).

In these experiments, three pressure sensors (one static and two piezoelectric sensors) are placed at three different places in the shock tube to capture the propagation of the shock wave. The test specimen is mounted with a rosette strain gauge in order to capture the small strains created by the shock wave impact (Figure 5).

2.3. Material Test System (MTS). The Material Test System (MTS) [20] is employed to examine the change in properties of test specimens. Given setup (Figure 6) can apply static and dynamic loads up to 100 metric tons. These tests were performed on specimens with and without being subjected to shock impact (Figure 7). Two kinds of tests were performed

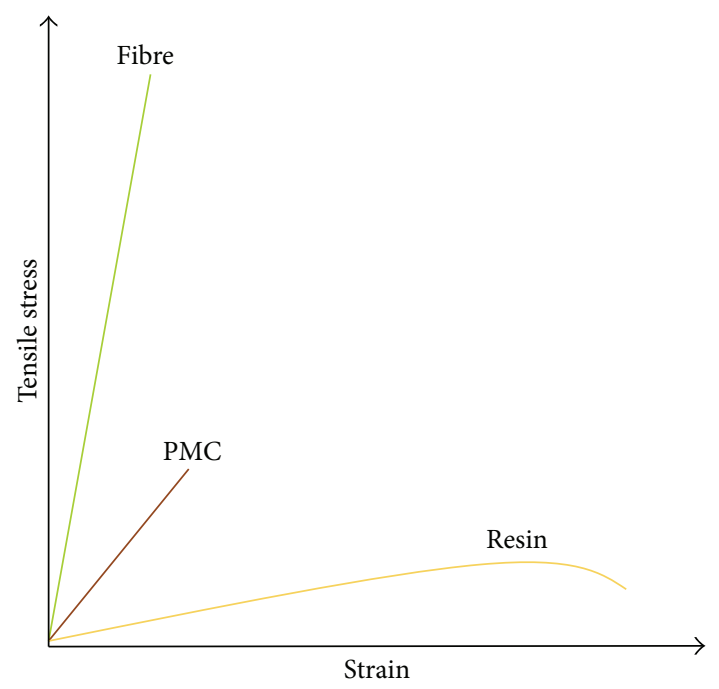

FIGURE 2: A stress/strain diagram, showing the fiber sheets in green, the resin (matrix) material in yellow, and the combined composite material (PMC) in the middle [16].

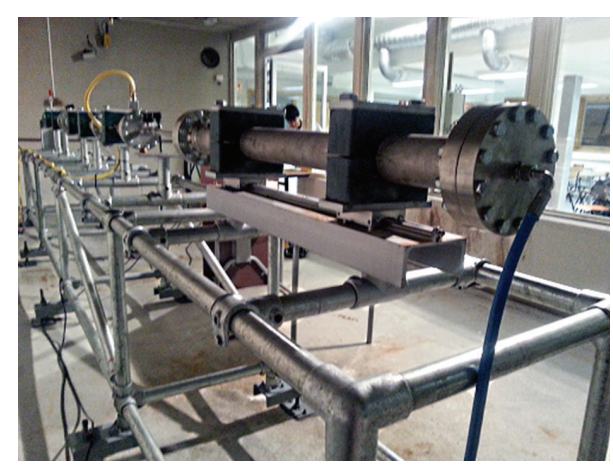

FIgUre 3: The shock tube. Driver section to the right (containing compressed air) and driven section to the left containing uncompressed water and a T-section for mounting the test specimen.

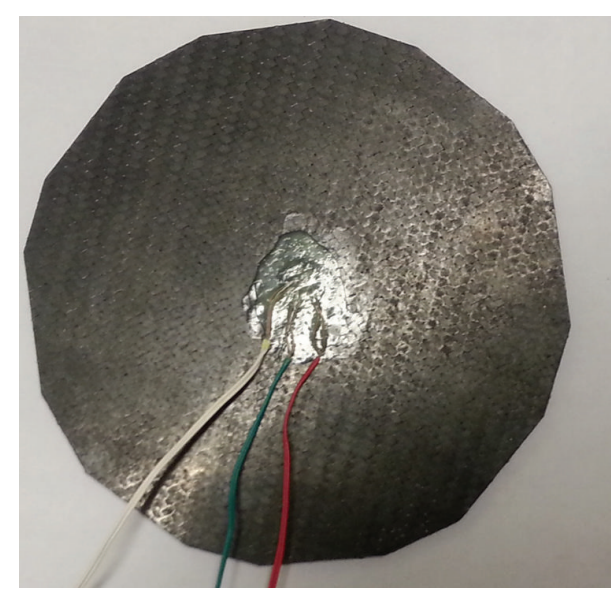

FIgURE 4: Rosette strain gauge attached to a CRFP specimen using cyanide-based glue. The three-colored wires are connections to three strain gauges at $45^{\circ}$ angles. The strain gauge is placed in the geometric center of the plate. 


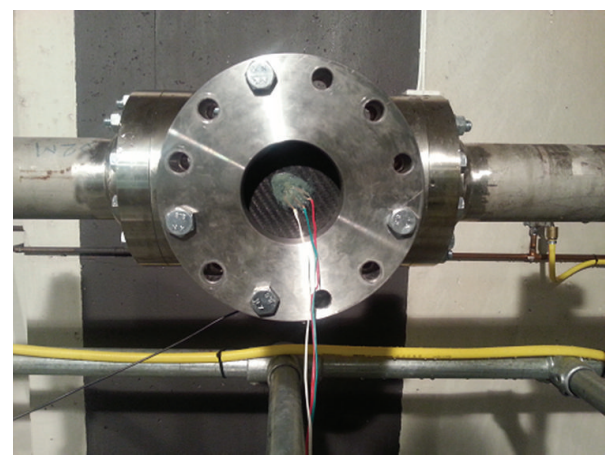

FIgURE 5: The T-section. The CRFP specimen is mounted on the T-section where the three-colored wires are the connection of the rosette strain gauge.

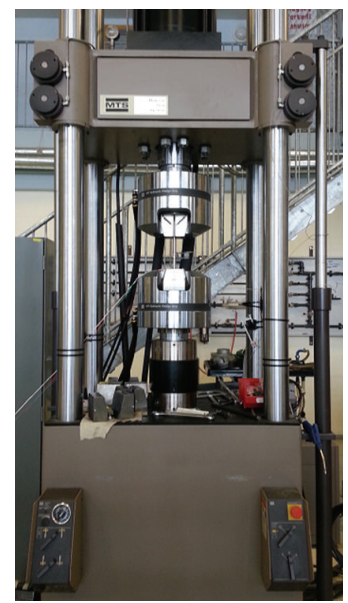

FIgURE 6: The MTS during tensile testing of a steel sample.

using MTS system: tensile (Figure 8) and flexural tests (Figure 9).

Rosette strain gauges were attached to the middle of each test piece for local strain. An average displacement gauge was also added to measure the total displacement of the test piece. The MTS was preprogrammed to apply tensile load, thus stretching the test piece until it ruptured. Tensile tests proved to be useful; however, clamps may create stress concentration points and hence lead to early failure. This can be avoided by performing flexural tests.

Flexural testing is more accurate in order to find the mechanical properties of test specimens. The experiment has been performed by bending the material using a pressure line in the middle of the test pieces (applied top down), while being placed on two supports (one on the left hand bottom side and one on the right hand bottom side) as shown in Figures 10(a) and 10(b). The middle (top down) line is applying pressure from the top onto the middle of the plane, bending the material until it suffers from total mechanical failure. The test piece used in flexural tests were prepared in the same way as for the tensile tests. In both tests, rosette strain gauge was placed in the geometric centre of the test piece. It is expected that the strain in longitudinal direction (from support to support) is going to be the highest with almost no strain in lateral direction.

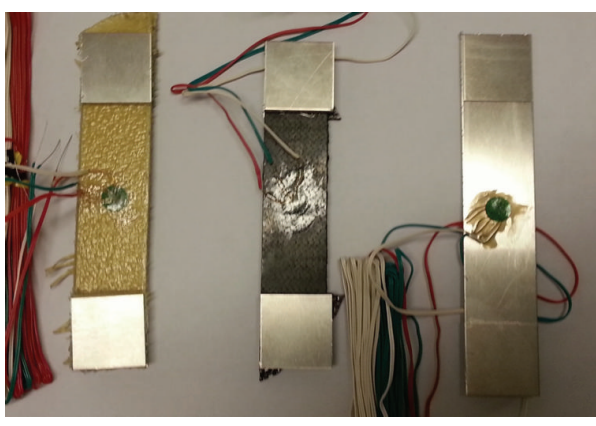

FIgURE 7: Kevlar, CRFP, and aluminium test samples. The ends are reinforced using aluminium plates for holding into the clamps. Rosette strain gauge is mounted for measuring the local strains.

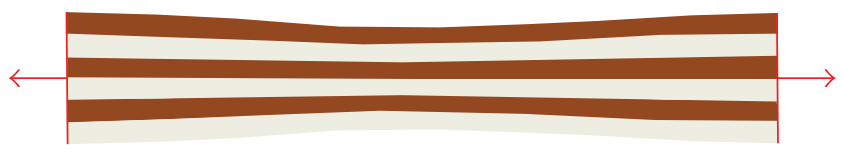

Figure 8: Tensile loads applied to a test piece. The material is stretched.

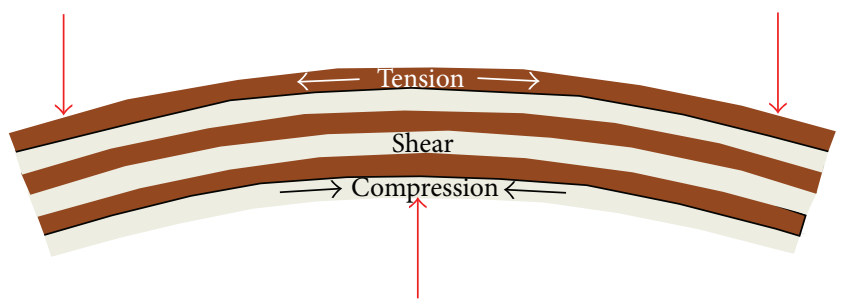

FIgure 9: Flexural loads applied to a material. Such load will give a tensile stress in the top surface, a shear stress in the middle, and compressive stresses in the bottom layer.

\section{Results}

3.1. Shock Tube and MTS Experiment Results. It is found that strain profile is linear mapping of driven pressure profile which can be seen from Figures 11(a) and 11(b). The experiments are repeated on the same test piece to confirm the validity of the results. Repeated experiments proved that CRFP test pieces can withstand shock pressure (Figure 11(a)); however, it is worth noting that applied shock pressure in these experiments did not result in strains for more than $25 \%$ of strain limit for rupture. It can be deduced that material behaves linearly under shock pressure loading which is further confirmed using transient FEM simulation by applying driven pressure loading data from shock tube experiments.

At this stage, it is important to see the response of CRFP test samples under slow loading; therefore, MTS tests are employed. At first, tensile tests are performed on samples as shown in Figure 7 where stress and strain data are recorded as shown in Figure 12. Tensile test is run until rupture of the test piece.

As shown in Figure 12, that CRFP test sample behaved linearly until rupture. The test specimen ruptured after approximately 37.4 seconds, gaining 10.8 millistrains. The overall 


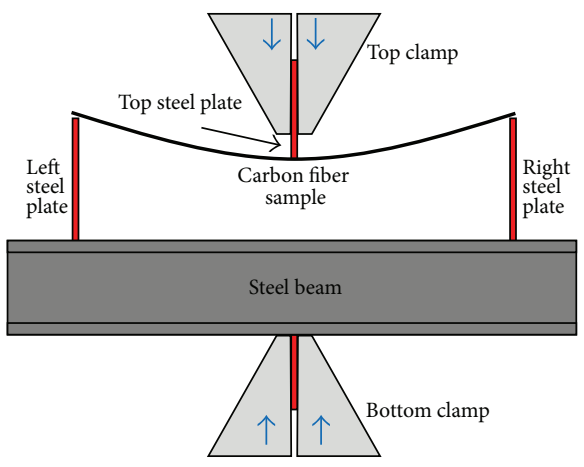

(a)

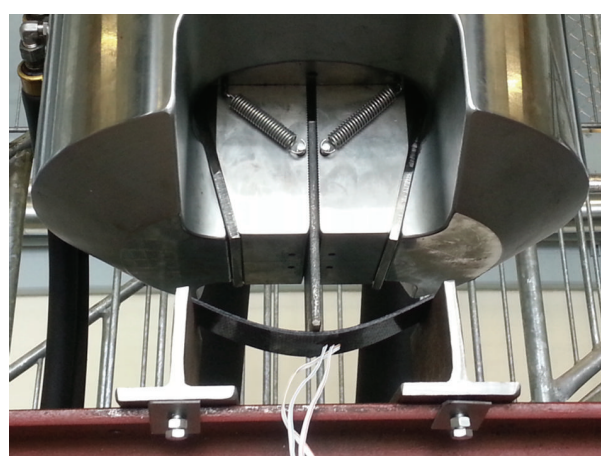

(b)

Figure 10: (a) A sketch of the flexural tests. (b) The actual flexural test performed in MTS.

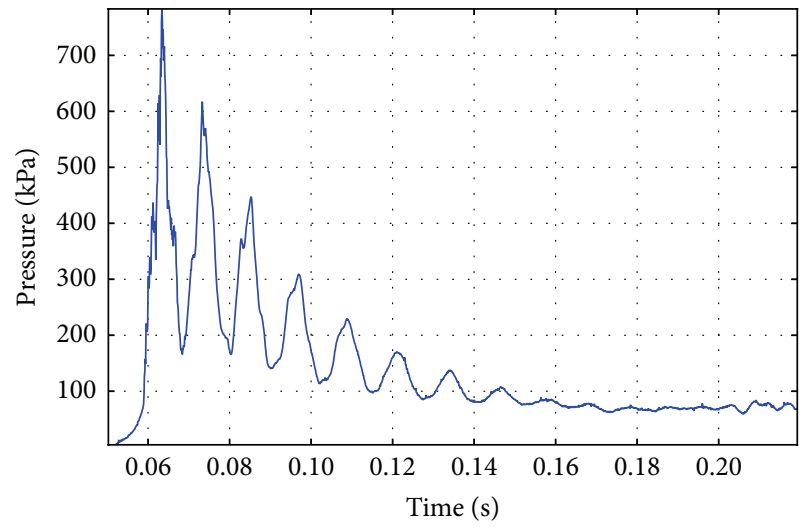

(a)

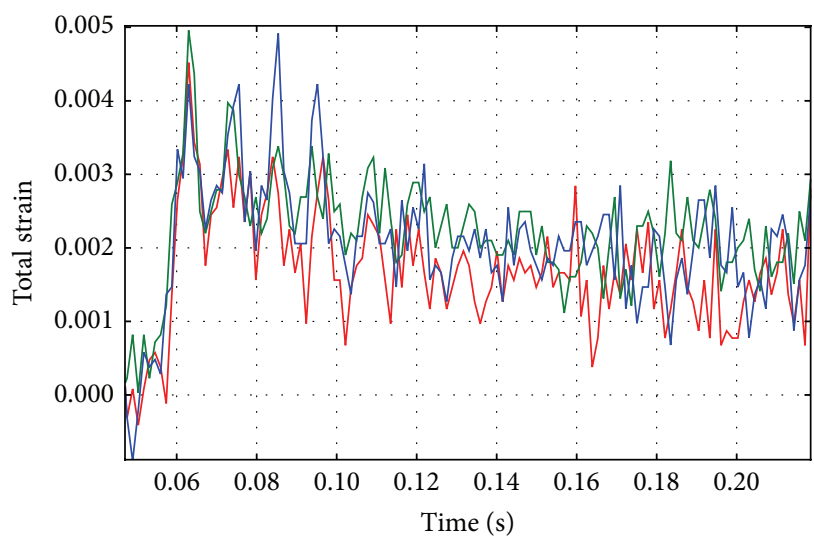

(b)

FIGURE 11: (a) Driven pressure profile in shock tube. (b) Rosette strain gauges response from four layers of CRFP specimen. Noise in strains after $0.16 \mathrm{~s}$ is due to experimental setup.

Young's modulus is found to be $28.897 \mathrm{GPa}$, whilst the modulus according to standard is provided as $26.751 \mathrm{GPa}$ [21]. A slight deviation is observed in results with repetition in the tests for which a likely cause is variation in the curing process in preparation of the samples.

Further, to confirm the linearity of CRFP response, flexural tests (Figures 10(a) and 10(b)) are performed in MTS. The results show the strains in $0^{\circ}(X), 45^{\circ}(X Y)$, and $90^{\circ}(Y)$ directions. The $X$-strain is largest (red), followed by the $X Y$ strain (green), and the smallest is the $Y$-strain (blue) as shown in Figure 13. The $X$-strain shows a maximum of 0.013 before the material ruptured after 298 seconds. This shows that the quasi-isotropic CRFP test specimen behaves linearly during low velocity, dynamic loads.

3.2. Finite Element Method Simulations Using ANSYS 14.0. The simulations $[22,23]$ are performed using experimental data gathered from shock tube experiments and the MTS. The 8-node 281-shell element provided in ANSYS 14.0 is used [23]. Mesh sensitivity analysis is carried out to ensure the quality of simulation results. In the analysis, the maximum strain is monitored with the mesh density. The value of maximum strain stabilizes with the increase in mesh density as shown in Figure 14. The FEM mesh used in simulation is shown in Figure 15. This represents the FEM model of 1200 elements (mesh density of " $4 x$ " from Figure 14). The simulated shell structure is $2.145 \mathrm{~mm}$ thick and $3.70 \mathrm{~cm}$ in diameter. The outer edges of the circular mesh are constrained in all degrees of freedom (DOFs). Transient pressure data from shock wave experiments is applied to the surface area. Obtained results are shown in Figure 16.

The strains obtained from simulations are one-to-one mapping to the pressure data and strain, confirming the results earlier seen in experiments. This demonstrates that there is a coherent response in the structure with the application of dynamic loading. Thus, the simulations also confirm that the response is linear during transient impulsive loading for quasi-isotropic CRFP.

\section{Conclusion}

Results from the shock tube experimental setup, Material Test System (with both tensile and flexural testing), and the Finite Element Method simulations using ANSYS 14.0 proved that, under dynamic loading, CRFP E720 composite behaves linearly. A good agreement between simulations and 


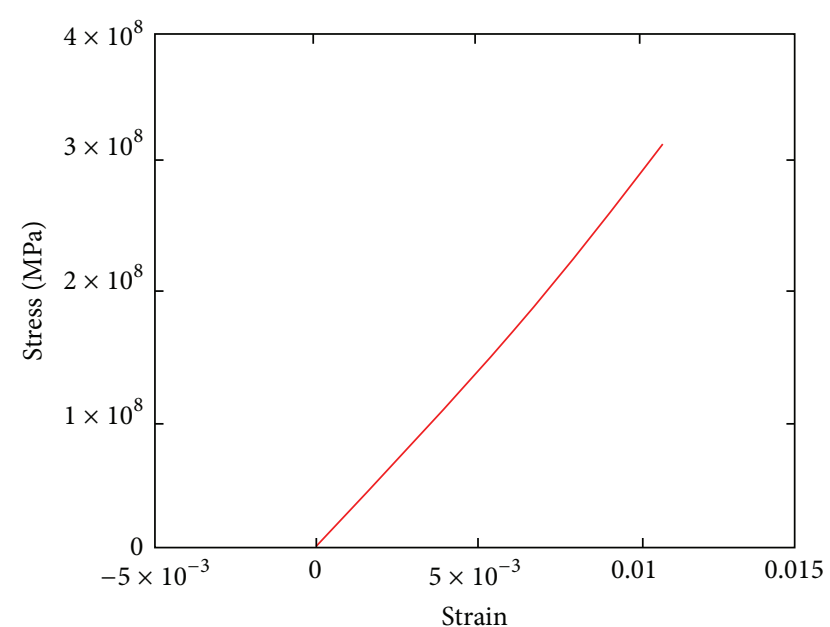

FIGURE 12: Stress/strain curve from the initial tensile tests on CRFP test specimens. The test piece ruptured after 37.4 seconds, gaining a strain of 10.8 millistrains in total.

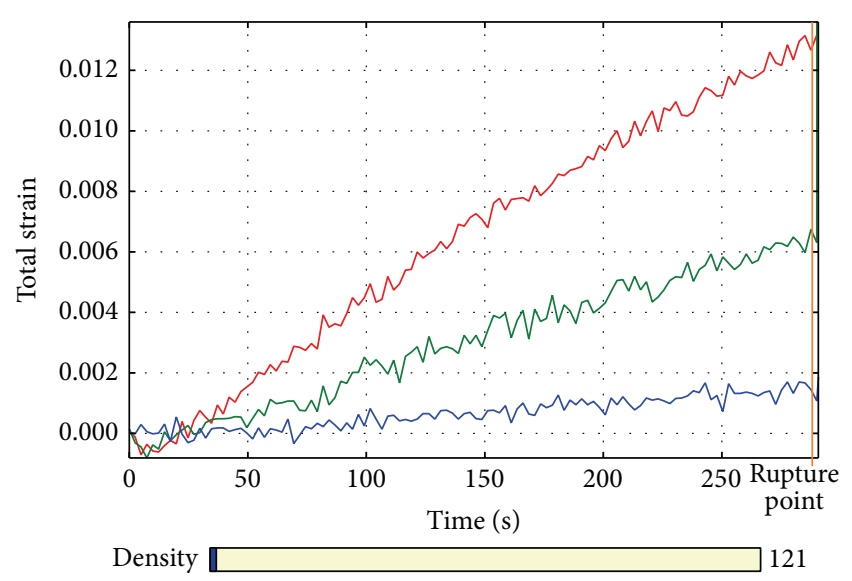

FIGURE 13: Strains over time gathered during flexural testing. $X$ strain in red, $X Y$-strain in green, and $Y$-strain in blue. $X$-strain is the largest strain, $X Y$-strain is about half of $X$-strain and $Y$-strain is the least.

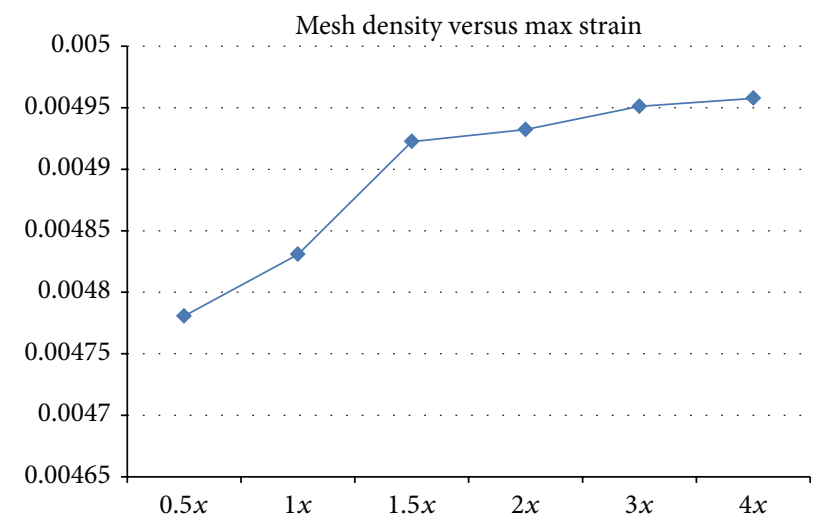

FIGURE 14: Results from the mesh sensitivity analysis $(x=300$ elements).

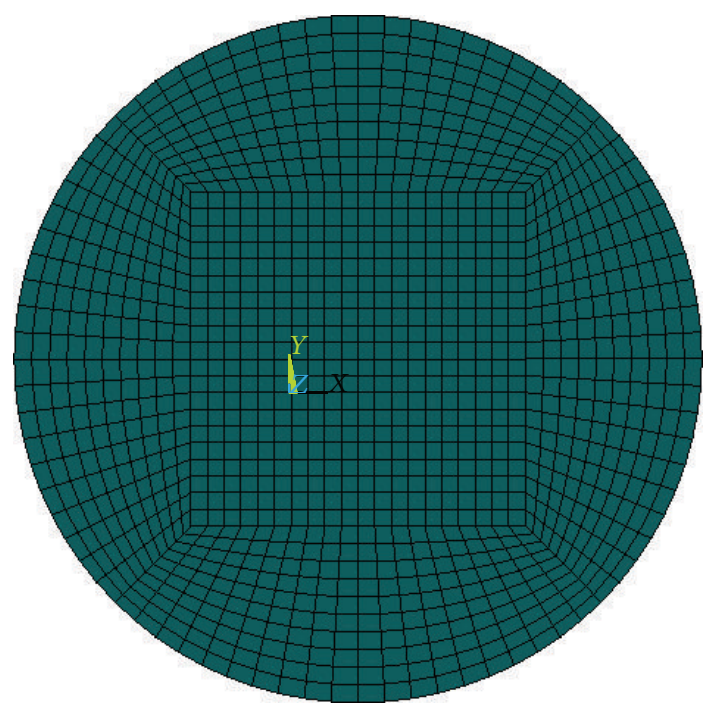

FIGURE 15: Mesh used in finite element analysis; shown is " $4 x$ " mesh density containing 1200 elements.

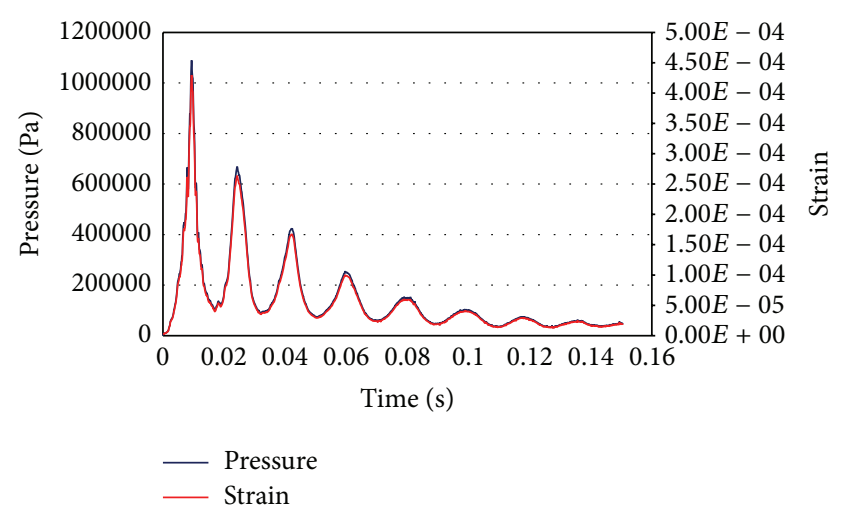

FIGURE 16: Pressure from experiment compared to equivalent strains from numerical simulation for an eight-layer CRFP.

experimental results confirms that Finite Element Method can be used for modelling of deforming structures under dynamic loading especially in the case as that discussed. The results from the given case prove that the mechanical behavior for quasi-isotropic CRFP E720 laminates is as similar during high speed, short time dynamic shock wave loads as it is for long time static, low velocity loads.

\section{Conflict of Interests}

The authors declare that there is no conflict of interests regarding the publication of this paper.

\section{References}

[1] D. Hull and T. W. Clyne, An Introduction to Composite Materials, Cambridge University Press, Cambridge, UK, 1996.

[2] Shock Wave and High-Strain-Rate Phenomena in Materials, Taylor \& Francis, 1992. 
[3] R. H. Cole, Underwater Explosions, Dover, Mineola, NY, USA, 1948.

[4] C. D. Sulfredge, R. H. Morris, and R. L. Sanders, "Calculating the effect of surface or underwater explosions on submerged equipment and structures," in Proceedings of the American Nuclear Society International Topical Meeting on Probabilistic Safety Analysis (PSA '05), pp. 73-86, September 2005.

[5] Y. K. Kim and S. Itoh, "A study on the behavior of underwater shock waves generated in a water container and its application to magnetic refrigeration material," The International Journal of Multiphysics, vol. 1, no. 3, pp. 291-302, 2007.

[6] Y. Nishimura, N. Kawaji, and S. Itoh, "Numerical analysis of the behavior of shock wave in spheroid vessel," The International Journal of Multiphysics, vol. 4, no. 4, pp. 317-328, 2010.

[7] S. Y. Knyazeva and V. K. Kedrinskiy, Hydrodynamics of Explosion: Experiments and Models, Springer, New York, NY, USA, 2006.

[8] A. C. Courtney, L. P. Andrusiv, and M. W. Courtney, "Oxyacetylene driven laboratory scale shock tubes for studying blast wave effects," Review of Scientific Instruments, vol. 83, no. 4, Article ID 045111, 2012.

[9] H. Ji, M. Mustafa, H. Khawaja, B. Ewan, and M. Moatamedi, "Design of water shock tube for testing shell materials," World Journal of Engineering, vol. 11, no. 1, pp. 55-60, 2014.

[10] P. R. Hampson and M. Moatamedi, "A review of composite structures subjected to dynamic loading," International Journal of Crashworthiness, vol. 12, no. 4, pp. 411-428, 2007.

[11] D. C. Barnes, S. M. Kusek, and D. A. Lascola, "Quasi-isotropic composite isogrid structure and method of making same," Patent US6007894 A, Google Patents, 1999.

[12] P. D. Soden, M. J. Hinton, and A. S. Kaddour, "Lamina properties, lay-up configurations and loading conditions for a range of fibre-reinforced composite laminates," Composites Science and Technology, vol. 58, no. 7, pp. 1011-1022, 1998.

[13] Multipreg E720, A. Composites, Editor 2010, http://www .ambercomposites.com/.

[14] ADHESIVE FILM EF72, “A. Composites, Editor 2010," http:// www.ambercomposites.com/.

[15] “SYNTATIC EPOXY RESIN FILM SC72A," 2009, http://www .ambercomposites.com/.

[16] A. B. Strong, Fundamentals of Composites Manufacturing, Materials, Methods and Applications, Society of Manufacturing Engineers, Dearborn, Mich, USA, 2nd edition, 2008.

[17] S. W. Tsai and E. M. Wu, "A general theory of strength for anisotropic materials," Journal of Composite Materials, vol. 5, pp. 58-80, 1971.

[18] J. Kapaya, A Technical Study of Shock Tube Experiment Setup, Narvik University College, 2013.

[19] D. S. Drumheller, Introduction to Wave Propagation in Nonlinear Fluids and Solids, Cambridge University Press, Cambridge, UK, 1998.

[20] R. Andreassen, Mathcad Test Analysis-MTS, Narvik University College, 2013.

[21] J. M. Corum, "Durability-based design properties of reference crossply carbon-fiber composite," in Other Information: PBD, Medium: ED, p. 218, 2001.

[22] ANSYS, "Academic Research, release 14.0".

[23] ANSYS, Academic Research, Theory Reference, in Structures, Static Analysis release 14.0. 

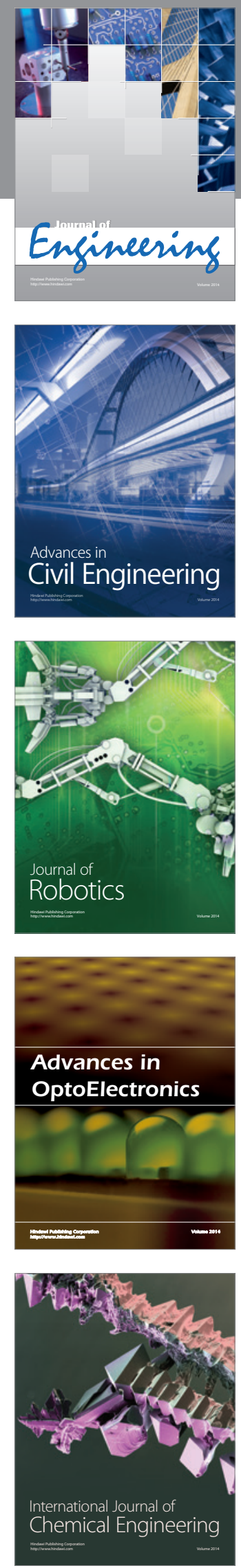

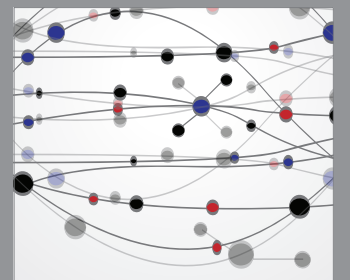

The Scientific World Journal
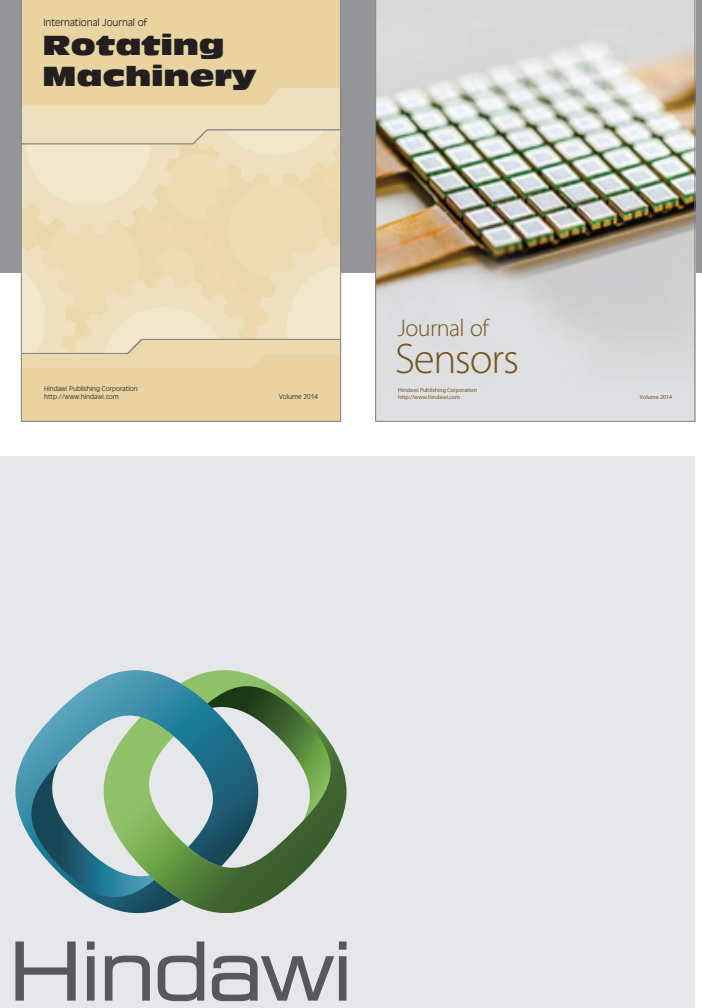

Submit your manuscripts at http://www.hindawi.com
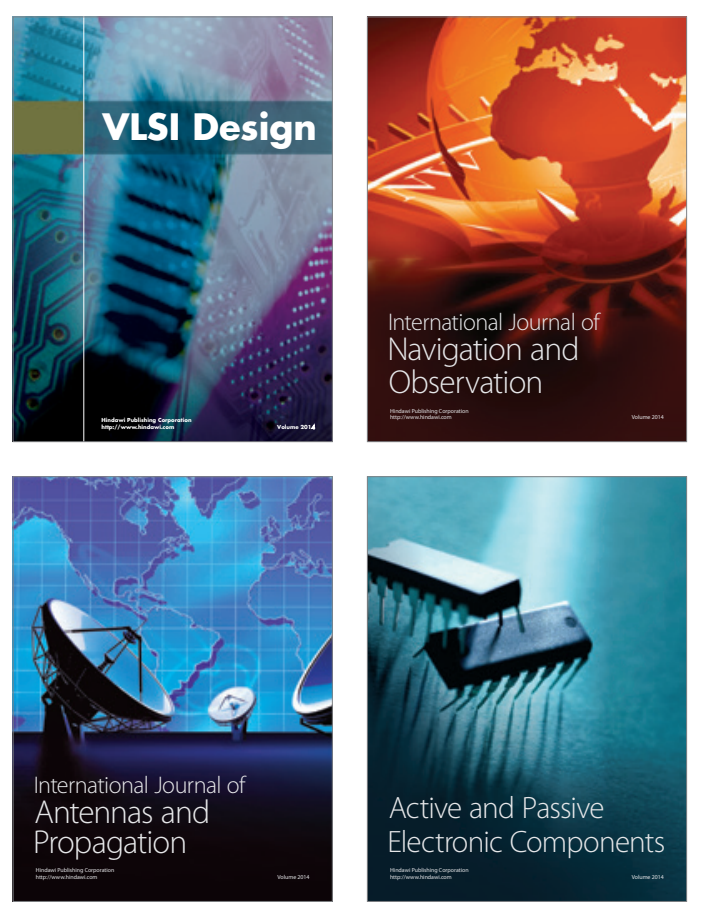
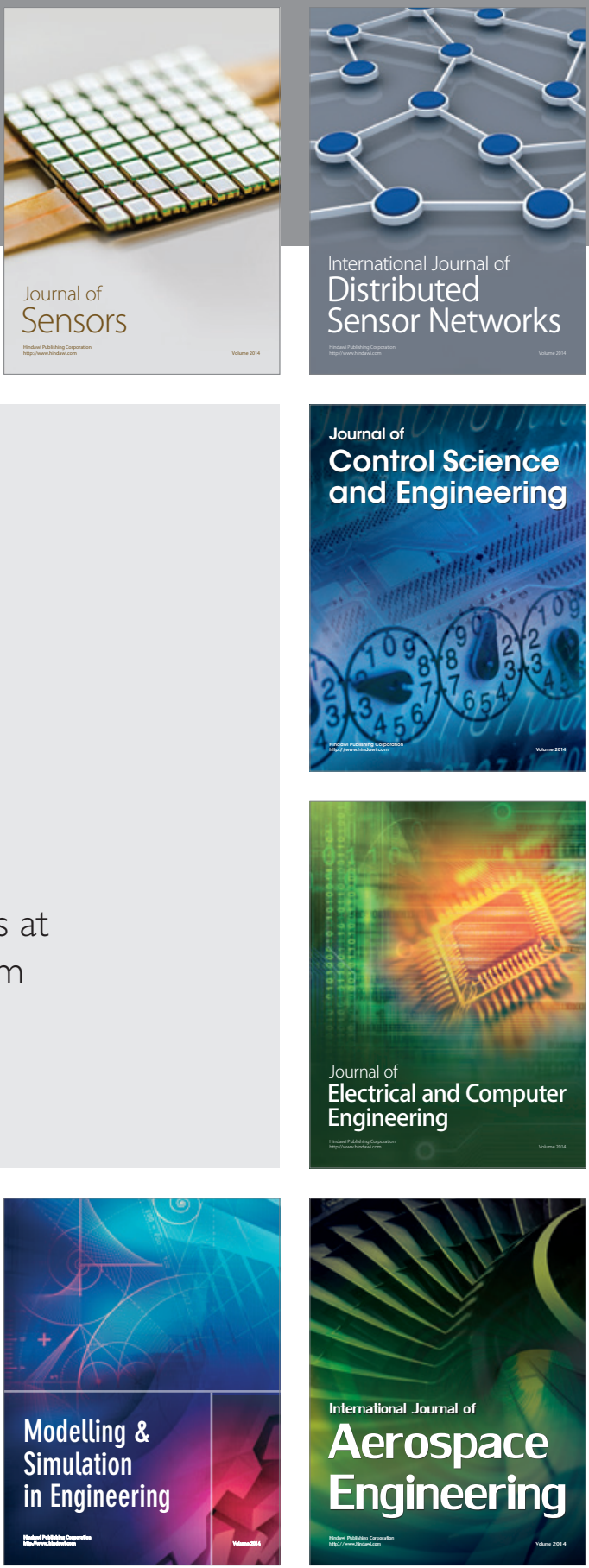

Journal of

Control Science

and Engineering
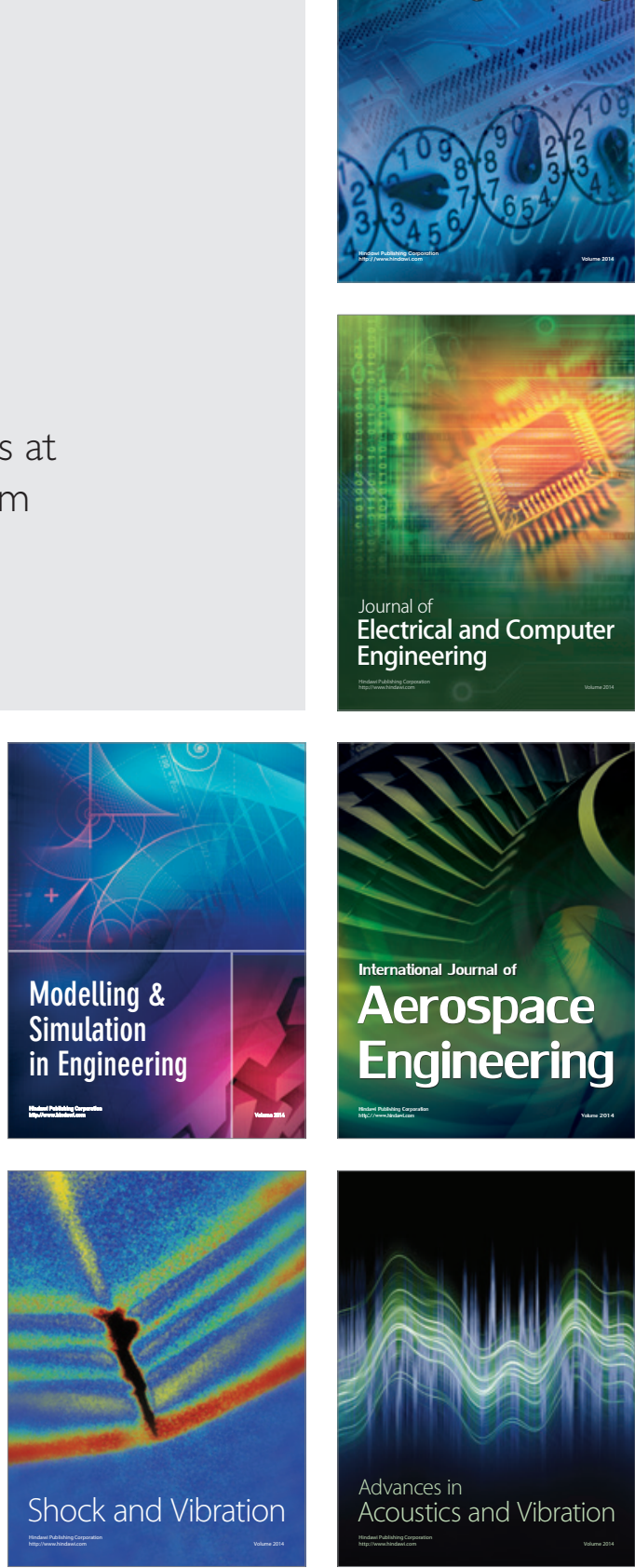